\title{
Harran Ovası Koşullarında Bazı Pamuk (Gossypium hirsutum L.) Çeşitlerinde Fenolojik Özelliklerin Belirlenmesi
}

\author{
Osman ÇOPUR ${ }^{1^{*}}$, Ibrahim Halil BIRGÜL ${ }^{2}$ \\ ${ }^{1}$ Harran Üniversitesi Ziraat Fakültesi Tarla Bitkileri Bölümü, 63100 Şanlıurfa \\ ${ }^{2}$ Harran Üniversitesi Fen Bilimleri Enstitüsü Tarla Bitkileri ABD, 63100 Şanlıurfa \\ "Sorumlu yazar: ocopur@harran.edu.tr
}

Öz

Pamuk bitkisinde vegetatif büyüme ile generatif büyüme arasında ideal bir denge bulunmaktadır. Bu denge her çevre için farklıdır. Bir çevre için ideal verimi, optimum vegetatif ve generatif büyüme ile sağlamak mümkündür. Bu amaçla, yetiştirilen pamuk çeşitlerinin çevre koşullarına olan tepkilerinin belirlenmesi gerekir. Bu çalışma, 10 pamuk çeşidinde bitki gelişimini izlemek amacıyla, Harran Üniversitesi Ziraat Fakültesi Eyyübiye Kampusu deneme alanında 2006 ve 2007 yılı yetiştirme sezonunda yürütülmüştür. Gossypium hirsutum L. türüne ait 10 pamuk çeşidi (Sayar-314, Erşan-92, BA-119, SureGrow-125, Stoneville-453, Carmen, DPL-388, GW Teks, DPL-5111 ve Fantom) bitki materyali olarak kullanılmışır. Deneme, tesadüf blokları deneme deseninde 3 tekerrürlü, her parsel 6 sıralı, sıra arası 70 $\mathrm{cm}$ ve sıra üzeri mesafe $15-20 \mathrm{~cm}$ olacak şekilde ekimi yapılmışır. Araştırma sonucunda; kütlü pamuk veriminin $318 \mathrm{~kg} \mathrm{da}^{-1}$ ile $487 \mathrm{~kg} \mathrm{da}^{-1}$ arasında değiştiği; en yüksek kütlü pamuk veriminin Stoneville 453 pamuk çeşidinde oluştuğu, boy boğum oranı (BBO), beyaz çiçek üstü boğum sayısı (BÇÜBS) ve en son beş boğum uzunluğunun çeşitlere göre değiştiği, özellikle çiçeklenme döneminde belirtilen parametrelerin arttığı ve daha sonra azaldığı saptanmıştır. Bitki izleme parametreleri arasında beyaz çiçek üstü boğum sayısı değerinin bitki izleme tekniği olarak etkin şekilde kullanılabileceği saptanmıştı. Ayrıca, çeşitlerin erkencilik özelliklerinin belirlenmesinde birinci el kütlü pamuk verimi ile birlikte beyaz çiçek üstü boğum sayısının 5’e ulaşma gün sayısı özelliğinin de kullanılabileceği belirlenmiştir.

Anahtar Kelimeler: Pamuk, BBO, BÇÜBS, Son Beş Boğum

\section{Determination of Phenological Characteristics on Some Cotton (Gossypium hirsutum L.) Varieties under the Harran Plain Conditions}

\begin{abstract}
Cotton has an ideal balance in terms of vegetative and generative growth. This balance varies for each environment. It is possible to ensure ideal yield for an environment with optimum vegetative and generative growth. For this purpose, it is necessary to determine reactions of cotton varieties cultivated to environmental conditions. This study was conducted in the experimental area of Eyyübiye Campus of Faculty of Agriculture, Harran University in 2006 and 2007 growing season in order to monitoring the growth of 10 cotton varieties. 10 cotton varieties (Sayar-314, Erşan-92, BA-119, SureGrow-125, Stoneville-453, Carmen, DPL-388, GW Teks, DPL-5111 and Fantom) belonging to Gossypium hirsutum L. species were used as plant material. The trial was performed using the randomized blocks design with 3 replications. Each plot was planted with 6 rows, the interrow distance was $70 \mathrm{~cm}$ and the intrarow distance was $15-20 \mathrm{~cm}$. It was found as a result of the study that the seed cotton yield varied between $318 \mathrm{~kg} \mathrm{da}^{-1}$ and $487 \mathrm{~kg} \mathrm{da}^{-1}$, Stoneville 453 gave the highest seed cotton yield, the height to node rate (HNR), the number of nodes above white flower (NAWF) and the height of the last five nodes varied between cotton varieties and the specified parameters increased during the flowering period and then decreased. Among plant monitoring parameters, the number of nodes above white flower was found to be effective as a plant monitoring technique. Also, it was found that the first hand picking and the
\end{abstract}


number of days required for the number of nodes above white flower to reach 5 could be used to determine earliness properties of cotton varieties.

Key Words : Cotton, HNR, NAWF, Last Five Node

\section{Giriş}

Bitkisel lifler içerisinde üretilen en önemli lif pamuktur. Dünyada üretilen 22.4 milyon ton lif pamuğun 737000 tonu Türkiye'de üretilmektedir. Türkiye'de üretilen pamuğun yaklaşık \%42'si Şanlıurfa ilinde ve üretilen pamuğun \%35'i Harran Ovasında üretilmektedir (Çopur, 2016). Harran Ovasında pamuk üreticilerinin en önemli sorunlarından birisi de üreticilerin büyüme sezonu boyunca hangi faktörlerin verimi etkilediği, bu faktörlerin nasıl gözlemlenebileceği ve hangi önlemleri alarak verimi ve kaliteyi artırma yoluna gidilebileceği sorunudur. Bu sorunların çözümünde, bazı bitki izleme tekniklerinin (plant monitoring techniques) kullanılarak birçoğunun çözümünde ümitvar olduklarını göstermiştir (Bölek ve ark., 2007). Kısaca bitkinin değişik büyüme dönemlerinin izlenmesi ve bitki büyümesine etki eden faktörlerin belirlenmesi olarak adlandırılan bitki haritalaması; pamuk bitkisi üzerinde detaylı veri toplama, sonra bu veriyle, bitkilerin çevrelerine nasıl cevap verdiklerini yorumlama ve buna göre kültürel tedbirleri uygulama olarak da tanımlanabilmektedir. illk olarak bitki fizyolojisini anlamak için bitki haritalaması, sonraları bitkinin stres koşullarına ve çevresine verdiği tepkiyi ölçen bir yöntem olarak önem kazanmıştır (Bourland ve ark., 1992).

Üreticiler bitki izleme tekniklerini kullanarak, pamuğun yetişme sezonu boyunca kullanılacak girdileri ayarlayabilir ve daha yüksek verim elde edebilirler. Örneğin, büyüme düzenleyicilerinin ve yaprak döktürücülerin (defoliantlar) kullanımı, sulama zamanı, ilaçlama zamanı ve gübreleme zamanının ayarlanması gibi işlemler bu tekniklere göre yapılabilir. Ayrıca, bitkinin yetişme periyodu süresince, vejetatif ve generatif büyüme arasındaki dengenin korunup korunamadığı tespit edilebilmektedir (Bölek ve ark. 2005).

Gübreleme ve sulama uygulamalarında genellikle, belirli bölgelerde yapılan tarla veya saksı deneme sonuçları esas alınmakta ve bunlara göre üreticiye öneriler yapılmaktadır. Ancak, pamuk bitkisinin büyüme ve gelişme özelliği yanında, çevresel faktörler göz önünde bulundurulduğunda, önerilere göre yapılan kültürel işlemlerden farklı sonuçlar alınabilmektedir.

Son yıllarda belirli aralıklarla bitki büyüme ve gelişmesinin gözlenmesine göre yetiştirme tekniklerinin uygulanması ele alınmaktadır. Pamuk bitkisinin büyüme ve gelişmesinin denetiminde; çiçeklenmeye kadar Ortalama Boğum Uzunluğu (OBU), çiçeklenmeden sonra ise OBU yanında, Beyaz Çiçek Üstü Boğum Sayısı (BÇÜBS) gibi yöntemlerin uygulanabileceği bildirilmektedir (Oosterhuis ve ark., 1993; Bölek ve ark., 2005). BÇÜBS'nın 7 ile 11 arasında olduğu dönemlerde, bitkinin oldukça iyi geliştiği; 5'e doğru düştüğünde ise çiçeklenmenin yavaşladığı ve sonra kesildiği (cut out); en düşük BÇÜBS değerinin bölgelere göre belirlenmesi gerektiği vurgulanmaktadır (McPherson ve ark., 1995).

Çeşit seçiminde; çeşitlerin karşılaştırılması açısından erkencilik kriterleri kullanılmaktadır. Erkencilik kriterlerinin başında birinci el kütlü oranı gelmektedir. Birinci el kütlü oranı, birinci elde toplanan 
kütlünün toplam kütlüye oranı olarak ifade edilmekte ve erkencilik kriteri olarak kullanılabileceği belirtilmektedir (Gençer ve Yelin, 1983). Ancak, birinci el kütlü oranı daha çok birinci el hasat tarihine bağlı kalmakta olup, özellikle solgunluk hastalığı görülen alanlarda bu oran yüksek çıkmakta ve erkenciliği belirlemede hatalara neden olabilmektedir. Bu amaçla, BÇÜBS'nın 5 değerine ulaşabilmesi için gereken gün sayısı da (days to NAWF) çeşitlerin erkencilik özelliklerinin belirlenmesinde kullanılabilmektedir (Iqbal ve ark., 2003).

Kaliforniya (A.B.D.) koşullarında Bitki Büyüme Oranının veya bir başka deyişle ortalama boğum uzunluğunun, fide döneminde $2.5 \mathrm{~cm}$ ile $3 \mathrm{~cm}$, ileri gelişme dönemlerinde $5 \mathrm{~cm}$ ile $7.5 \mathrm{~cm}$ arasında olduğu ve pamuk bitkilerinin belirli aralarla ölçümlenerek saptanan rakamlara göre gübreleme, sulama, ve hormon uygulama zamanlarına karar verilebileceği belirtilmektedir (Kerby ark., 1993). Boy boğum oranının azot dozlarından etkilendiği, en yüksek değerin 16 ve $24 \mathrm{~kg} \mathrm{da}{ }^{1}$ dozundan elde edildiği, azot dozlarının en üst beş boğum uzunluğunu ve BÇÜBS arttırdığı ve $B C ̧ U ̈ B S$ değerinin bitki büyüme ve gelişmesini izlemede etkin olarak kullanılabileceği belirtilmektedir (Yolcu, 2009). Ülkemizde özellikle, önemli pamuk üretim alanlarından birisi olan Harran Ovasında pamukta bitki izleme teknikleri ile ilgili yeterli çalışma bulunmamaktadır.

$\mathrm{Bu}$ çalışma, Güneydoğu Anadolu Bölgesinde sertifikalı olan pamuk çeşitlerinin, Harran Ovası koşullarında farklı bitki izleme teknikleri ile bitki gelişiminin izlenmesi ve bu konuda yapılacak çalışmalara kaynak oluşturması amacıyla yürütülmüştür.

\section{Materyal ve Metot}

Deneme, Harran Üniversitesi Ziraat Fakültesi Eyyübiye Kampüsü deneme alanında 2006 ve 2007 yıllarında yürütülmüştür. Anılan alanın denizden ortalama yüksekliği $465 \mathrm{~m}$ olup, $37^{\circ} 08^{\prime} \mathrm{N}$ enlem ve $38^{\circ} 46^{\prime} E$ boylamlarında yer almaktadır. Deneme alanı killi (\% 60), organik madde oranı düşük (\% 1.2), pH değeri 7.2' dir (Çizelge 1). Deneme alanı íkizce toprak serisi (Vertic Calciorthid Aridisol) olarak sınıflandırılmıştır (Anonim 2006). Harran ovası, yarı kurak iklim koşullarına sahip olup, yazları sıcak ve kurak, kışları ise ılık ve yağışlıdır. Yazın sıcaklık $44.8{ }^{\circ} C^{\prime}$ ye kadar çıkabilmektedir. Bölgede toplam yağış miktarı 2006 ve 2007 yıllarında 355.2 ve $364.2 \mathrm{~mm}$ olarak gerçekleşmiştir (Çizelge 2).Uzun yıllar ortalama sıcaklık $18.3{ }^{\circ} \mathrm{C}$, ortalama nem $\% 50.3$ ve ortalama rüzgar hızı $2.2 \mathrm{~m} \mathrm{~s}^{-1^{\prime}} \operatorname{dir}$ (Anonim, 2009).

Çizelge 1. Deneme alanına ait bazı toprak özellikleri

Table 1. Several soil properties of the study area

\begin{tabular}{|c|c|c|c|c|c|c|c|c|c|c|c|}
\hline \multirow[t]{2}{*}{$\begin{array}{c}\text { Derinlik } \\
(\mathrm{cm})\end{array}$} & \multirow[t]{2}{*}{$\begin{array}{c}\mathrm{HA} \\
\left(\mathrm{g} \mathrm{cm}^{-3}\right)\end{array}$} & \multirow[t]{2}{*}{$\begin{array}{l}\text { OM } \\
(\%)\end{array}$} & \multicolumn{3}{|c|}{$\begin{array}{c}\text { Toprak partiküllerinin } \\
\text { dağılımı (\%) }\end{array}$} & \multirow[t]{2}{*}{$\mathrm{pH}$} & \multirow[t]{2}{*}{$\begin{array}{c}\mathrm{N} \\
\left(\mathrm{kg} \mathrm{ha}^{-1}\right)\end{array}$} & \multirow[t]{2}{*}{$\begin{array}{c}\mathrm{P}_{2} \mathrm{O}_{5} \\
\left(\mathrm{~kg} \mathrm{ha}^{-1}\right)\end{array}$} & \multirow[t]{2}{*}{$\begin{array}{c}\mathrm{K}_{2} \mathrm{O} \\
\left(\mathrm{kg} \mathrm{ha}^{-1}\right)\end{array}$} & \multirow[t]{2}{*}{$\begin{array}{l}\text { TK } \\
(\%)\end{array}$} & \multirow[t]{2}{*}{$\begin{array}{l}\text { SSN (\%) } \\
\text { PWP(\%) }\end{array}$} \\
\hline & & & Kum & Silt & Kireç & & & & & & \\
\hline $0-30$ & 1.37 & 1.2 & 7 & 34 & 59 & 7.3 & 25 & 27 & 1280 & 31.5 & 22.2 \\
\hline $30-60$ & 1.40 & 0.8 & 17 & 25 & 58 & 7.2 & 12 & 20 & 900 & 31.8 & 22.6 \\
\hline $60-90$ & 1.43 & 0.6 & 20 & 21 & 59 & 7.2 & 6 & 17 & 810 & 32.3 & 21.5 \\
\hline $90-120$ & 1.43 & 0.5 & 19 & 20 & 62 & 7.2 & - & - & - & 32.5 & 21.5 \\
\hline
\end{tabular}

HA: Hacim ağırlığı, $\quad$ OM: Organik madde, TK: Tarla kapasitesi, SSN: Sürekli solma noktası

(VW: volume weight), (OM:organic matter) (FC: field capacity) (PWP:permanent wilting point) 
Çizelge 2. 2006 ve 2007 yılları pamuk yetiştirme sezonunda bazı iklim özellikleri

Table 2. Climatic data of the cotton crop growing season for the years of 2006 and 2007

\begin{tabular}{|c|c|c|c|c|c|c|}
\hline & $\begin{array}{l}\text { Mayıs } \\
\text { May }\end{array}$ & $\begin{array}{l}\text { Haziran } \\
\text { June }\end{array}$ & $\begin{array}{l}\text { Temmuz } \\
\text { July }\end{array}$ & $\begin{array}{l}\text { Ağustos } \\
\text { August }\end{array}$ & $\begin{array}{c}\text { Eylül } \\
\text { September }\end{array}$ & $\begin{array}{l}\text { Ekim } \\
\text { October }\end{array}$ \\
\hline \multicolumn{7}{|c|}{2006} \\
\hline Minimum hava sıcaklığı $\left({ }^{\circ} \mathrm{C}\right)$ & 13.4 & 18.0 & 20.8 & 22.8 & 16.0 & 10.1 \\
\hline \multicolumn{7}{|l|}{ Min. air temperature $\left({ }^{\circ} \mathrm{C}\right)$} \\
\hline Maks. hava sıcaklığı ( $\left.{ }^{\circ} \mathrm{C}\right)$ & 39.1 & 44.0 & 43.0 & 44.5 & 40.0 & 33.5 \\
\hline \multicolumn{7}{|l|}{ Max. air temperature $\left({ }^{\circ} \mathrm{C}\right)$} \\
\hline Ortalama hava sıcaklığı $\left({ }^{\circ} \mathrm{C}\right)$ & 23.8 & 30.8 & 32.2 & 33.4 & 27.2 & 20.6 \\
\hline \multicolumn{7}{|l|}{ Average air temp. $\left({ }^{\circ} \mathrm{C}\right)$} \\
\hline Nisbi nem (\%) & 45.9 & 40.8 & 45.5 & 44.6 & 42.3 & 61.5 \\
\hline \multicolumn{7}{|l|}{ Relative humidity (\%) } \\
\hline \multicolumn{7}{|l|}{ Wind speed $\left(\mathrm{m} \mathrm{s}^{-1}\right)$} \\
\hline Toplam yağış (mm) & 17.4 & 0.3 & 0.3 & ---- & ----- & 42.5 \\
\hline \multicolumn{7}{|l|}{ Total precipitation $(\mathrm{mm})$} \\
\hline \multicolumn{7}{|c|}{2007} \\
\hline $\begin{array}{l}\text { Minimum hava sıcaklığı }\left({ }^{\circ} \mathrm{C}\right) \\
\text { Min. air temperature }\left({ }^{\circ} \mathrm{C}\right)\end{array}$ & \multicolumn{5}{|c|}{ Min. air temperature $\left({ }^{\circ} \mathrm{C}\right)$} & 9.8 \\
\hline $\begin{array}{l}\text { Maksimum hava sıcaklığı }\left({ }^{\circ} \mathrm{C}\right) \\
\text { Max. air temperature }\left({ }^{\circ} \mathrm{C}\right)\end{array}$ & \multicolumn{5}{|c|}{ Max. air temperature $\left({ }^{\circ} \mathrm{C}\right)$} & 34.2 \\
\hline Ortalama hava sıcaklığı $\left({ }^{\circ} \mathrm{C}\right)$ & 25.4 & 30.4 & 34.0 & 32.2 & 28.4 & 21.6 \\
\hline \multicolumn{7}{|l|}{ Average air temperature $\left({ }^{\circ} \mathrm{C}\right)$} \\
\hline Nispi nem (\%) & 54.0 & 36.9 & 31.3 & 41.9 & 36.4 & 47.7 \\
\hline \multicolumn{7}{|l|}{ Relative humidity (\%) } \\
\hline \multicolumn{7}{|l|}{ Wind speed $\left(\mathrm{m} \mathrm{s}^{-1}\right)$} \\
\hline $\begin{array}{l}\text { Toplam yağış }(\mathrm{mm}) \\
\text { Total precipitation }(\mathrm{mm})\end{array}$ & 8.8 & 0.8 & 8.0 & 3.2 & ---- & 14.5 \\
\hline
\end{tabular}

Denemeler tesadüf blokları deneme desenine göre 3 tekerrürlü olarak kurulmuştur. Deneme materyali olarak seçilen pamuk çeşitleri (Sayar-314, Erşan-92, BA-119, SureGrow-125, Stoneville-453, Carmen, DPL-388, GW Teks, DPL-5111 ve Fantom) Güneydoğu Anadolu Bölgesi pamuk alanları için tescil edilen çeşitlerdir.

Ekim işlemi, 2006 yılında 05 Mayıs ve 2007 yılında ise 7 Mayıs tarihinde pamuk deneme mibzeri ile $70 \mathrm{~cm}$ sıra arası mesafesinde, $10 \mathrm{~m}$ uzunluğunda ve 6'şar sıralı olarak yapıımıştır. Çıkıştan sonra bitkiler 4-5 yapraklı olduğu dönemde sıra üzeri mesafe $15-20 \mathrm{~cm}$ olacak şekilde (her sırada 50 ile 60 bitki) seyreltilmiştir. Deneme yıllarında yetiştirme sezonu boyunca, bitkiler 2 kez el, 3 defa makine çapası ile çapalanmış ve 10 defa karık usulü ile sulanmıştır. Ekimle birlikte dekara saf olarak $8 \mathrm{~kg}$ azot ve $8 \mathrm{~kg}$ fosfor (20.20.0 kompoze gübre) ile çiçeklenme başlangıcında ise $8 \mathrm{~kg}$ azot (\%33 Amonyum nitrat) üst gübre olarak uygulanmıştır. Denemede uygulanan kültürel işlemler, bölgede yapılan çalışmalar esas alınarak yapılmıştır. Hasatlar; 2006 ve 2007 yıllarında, birinci el hasat 5 Eylül, ikinci el hasat ise 20 Eylül ve üçüncü el hasat ise 5 Ekim tarihinde olmak üzere üç defada ve elle yapılmıştır.

Çalışmada incelenen kütlü pamuk verimi ve birinci el kütlü pamuk verimi Worley ve ark., (1976), beyaz çiçek üstü boğum sayısı (BÇÜBS), bitki boyunun boğum sayısına oranı (BBO), en son 5 boğum uzunluğu (ESBBU) ve BÇÜBS'nın 5'e ulaşma gün sayısı Landivar ve 
Benedict, (1996), Oosterhuis ve ark., (1993) ve Teague ve ark., (2000) belirttiği yöntemler uyarınca saptanmıştır. Bitki boyunun boğum sayısına oranı ve son 5 boğum uzunluğu ölçümlerine her iki yılda da, 21 Haziran'da başlanmış ve 20 Eylül'de tamamlanmıştır. Beyaz çiçek üstü boğum sayısı ölçümleri ise her iki yılda da 11 Temmuz'da başlanmış ve 17 Ağustos'ta tamamlanmıştır. Bitkisel ölçümler denemenin yürütüldüğü her iki yılda da 21 Haziranda başlanmış ve her parselde 10 bitki belirlenerek birer hafta aralıklarla yapılmıştır. Beyaz çiçek üstü boğum sayısının 5'e ulaşma gün sayısı ise gün olarak hesaplanmıştır.

Elde edilen veriler MSTATC paket programı kullanılarak her yıl ayrı ayrı analiz edilmiş ve ortalamalar LSD testine göre karşılaştırılmıştır (Anonymous, 1989).

\section{Araştırma Bulguları ve Tartışma}

Beyaz çiçek üstü boğum sayısı (BÇÜBS)

2006 ve 2007 yıllarında pamuk çeşitlerine göre birer hafta aralıklarla saptanan beyaz çiçek üstü boğum sayısına ilişkin ortalama değerler ve LSD testine göre oluşan gruplar Çizelge 3 ve 4'de verilmiştir.

Çizelge 3 ve 4'den, 2006 ve 2007 yıllarında, ekimden 66 gün sonra yapılan beyaz çiçek üstü boğum sayımlarının Carmen çeşidi hariç ortalama 9-10 adet/bitki olduğu; 73. günde 8.5-9 adet/bitki, 81. günde 7-7.5 adet/bitki, 88. günde 5.6-5.8 adet/bitki, 95 . günde 3.8-4.90 adet/bitki ve 103. günde ortalama $\quad 0.5-2$ arasına düştüğü izlenebilmektedir. Çeşitlere göre saptanan ortalama çiçeklenme süresi (Carmen ve SG125 hariç) yaklaşık 35-40 gün kadar devam etmektedir. Tüm çeşitlerde özellikle 88 . günden sonra (çiçeklenmenin 25. gününden sonra) bitkilerin büyümelerinin yavaşladığı ve 103. günde büyümenin hemen hemen durduğu izlenebilmektedir. Beyaz çiçek üstü boğum sayısı, Bourland ve ark., (1992) tarafından geliştirilmiş bir büyüme izleme tekniğidir. Belirtilen yöntem uyarınca bitkilerde ölçüm yapılan dönemde normal olarak geliştiği ve herhangi bir stres koşulunun oluşmadığı izlenebilmektedir. Stres koşullarında beyaz çiçek üstü boğum sayısı değeri azalmakta ve erken dönemde bitki olgunlaşmaya başlamaktadır. Bölgemizde etkili çiçeklenme dönemi yaklaşık 30-35 gün kadar sürmekte ve daha sonra bitkiler olgunlaşmaya başlamaktadır. Bulgularımı, Oosterhuis ve ark., (1993), Silvertooth ve Norton, (1999), Oosterhuis ve Robertson, (2000) ve Soomro ve ark., (2005)'nın bulguları ile uyum içerisindedir. Bu durum, beyaz çiçek üstü boğum sayısının bitki büyümesini izleme yönünden bölgemizde kullanılabileceğini göstermektedir. Nitekim Bölek ve ark., (2007) ve Yolcu, (2009) BÇÜBS'nın çiçeklenmenin başlangıcında bölgelere ve kültürel uygulamalara göre değişmekle birlikte yaklaşık 10 , cut-out zamanında 5 dolayında olması gerektiği ve anılan özelliğin bitki büyüme ve gelişimini izlemede etkin olarak kullanılabileceğini bildirmektedirler. 
Çizelge 3. 2006 yılında, farklı pamuk çeşitlerinde ve farklı günlerde elde edilen ortalama beyaz çiçek üstü boğum sayısı değerleri ile LSD testine göre oluşan gruplar

Table 3. Means of number of nodes above white flower according to some cultivars and LSD testing groups in years to 2006

\begin{tabular}{lcccccc}
\hline & \multicolumn{5}{c}{ Ekimden sonraki günler (Days of after sowing) } \\
\cline { 2 - 6 } Çeşitler & 66 & 73 & 81 & 88 & 95 & 103 \\
Varieties & $(11.07 .06)$ & $(18.07 .06)$ & $(26.07 .06)$ & $(02.08 .06)$ & $(09.08 .06)$ & $(17.08 .06)$ \\
\hline STV-453 & $10.13 \mathrm{bc} *$ & $9.71 \mathrm{ab}$ & $7.29 \mathrm{~d}$ & $6.32 \mathrm{~b}$ & $4.54 \mathrm{~b}$ & $0.00 \mathrm{c}$ \\
SG-125 & $10.53 \mathrm{~b}$ & $9.50 \mathrm{bc}$ & $7.11 \mathrm{de}$ & $5.39 \mathrm{de}$ & $3.72 \mathrm{c}$ & $2.00 \mathrm{~b}$ \\
BA-119 & $10.04 \mathrm{c}$ & $9.29 \mathrm{c}$ & $6.45 \mathrm{~h}$ & $5.00 \mathrm{e}$ & $3.67 \mathrm{c}$ & $0.00 \mathrm{c}$ \\
Carmen & $0.00 \mathrm{~d}$ & $9.83 \mathrm{a}$ & $8.65 \mathrm{a}$ & $7.00 \mathrm{a}$ & $5.08 \mathrm{a}$ & $3.99 \mathrm{a}$ \\
DPL-388 & $10.42 \mathrm{bc}$ & $8.52 \mathrm{f}$ & $6.96 \mathrm{ef}$ & $5.44 \mathrm{~d}$ & $2.83 \mathrm{~d}$ & $0.00 \mathrm{c}$ \\
DPL-5111 & $10.21 \mathrm{bc}$ & $8.84 \mathrm{e}$ & $6.75 \mathrm{f}$ & $5.47 \mathrm{~d}$ & $3.00 \mathrm{~d}$ & $0.00 \mathrm{c}$ \\
GW Teks & $10.55 \mathrm{~b}$ & $9.24 \mathrm{~cd}$ & $6.82 \mathrm{fg}$ & $6.00 \mathrm{bc}$ & $3.09 \mathrm{~d}$ & $0.00 \mathrm{c}$ \\
Fantom & $10.50 \mathrm{~b}$ & $9.49 \mathrm{bc}$ & $8.28 \mathrm{~b}$ & $5.78 \mathrm{~cd}$ & $2.92 \mathrm{~d}$ & $0.00 \mathrm{c}$ \\
Sayar-314 & $10.46 \mathrm{bc}$ & $8.95 \mathrm{de}$ & $8.58 \mathrm{a}$ & $6.39 \mathrm{~b}$ & $4.57 \mathrm{~b}$ & $0.00 \mathrm{c}$ \\
Erşan-92 & $11.03 \mathrm{a}$ & $9.94 \mathrm{a}$ & $7.55 \mathrm{c}$ & $5.44 \mathrm{~d}$ & $4.83 \mathrm{a}$ & $0.00 \mathrm{c}$ \\
\hline Ort. (Mean) & 9.39 & 9.33 & 7.44 & 5.83 & 3.83 & 0.54 \\
\hline LSD(0.05) & 0.454 & 0.307 & 0.203 & 0.437 & 0.260 & 0.188 \\
*: Aynı harf grubu içerisinde yer alan konular arasında (dikey) istatistiki olarak önemli düzeyde $(0.05)$ bir farklılık bulunamamıştır \\
*Means shown with the same column (vertical) are not significantly differently at p 0.05 probability level.
\end{tabular}

Çizelge 4. 2007 yılında, farklı pamuk çeşitlerinde ve farklı günlerde elde edilen ortalama beyaz çiçek üstü boğum sayısı değerleri ile LSD testine göre oluşan gruplar

Table 4. Means of number of nodes above white flower according to some cultivars and LSD testing groups in years to 2007

\begin{tabular}{lcccccc}
\hline & \multicolumn{6}{c}{ Ekimden sonraki günler (Days of after sowing) } \\
\cline { 2 - 6 } Çeşitler & 66 & 73 & 81 & 88 & 95 & 103 \\
Varieties & $(11.07 .07)$ & $(18.07 .07)$ & $(26.07 .07)$ & $(02.08 .07)$ & $(09.08 .07)$ & $(17.08 .07)$ \\
\hline STV-453 & $9.00 \mathrm{c}^{*}$ & $8.27 \mathrm{bcd}$ & $7.63 \mathrm{~b}$ & $6.37 \mathrm{a}$ & $5.43 \mathrm{ab}$ & $5.10 \mathrm{a}$ \\
SG-125 & $9.27 \mathrm{bc}$ & $8.40 \mathrm{bc}$ & $7.80 \mathrm{ab}$ & $5.40 \mathrm{~b}$ & $5.13 \mathrm{c}$ & $2.00 \mathrm{~cd}$ \\
BA-119 & $9.33 \mathrm{bc}$ & $8.40 \mathrm{bc}$ & $6.00 \mathrm{~d}$ & $5.40 \mathrm{~b}$ & $5.20 \mathrm{bc}$ & $2.33 \mathrm{c}$ \\
Carmen & $9.07 \mathrm{c}$ & $8.10 \mathrm{bcd}$ & $6.37 \mathrm{~d}$ & $5.60 \mathrm{~b}$ & $5.67 \mathrm{a}$ & $5.30 \mathrm{a}$ \\
DPL-388 & $9.80 \mathrm{ab}$ & $8.00 \mathrm{~cd}$ & $6.47 \mathrm{~cd}$ & $5.10 \mathrm{~b}$ & $5.10 \mathrm{c}$ & $0.00 \mathrm{e}$ \\
DPL-5111 & $9.13 \mathrm{c}$ & $7.67 \mathrm{~d}$ & $5.90 \mathrm{~d}$ & $5.37 \mathrm{~b}$ & $5.07 \mathrm{c}$ & $1.67 \mathrm{~d}$ \\
GW Teks & $9.73 \mathrm{~b}$ & $9.37 \mathrm{a}$ & $5.83 \mathrm{~d}$ & $5.63 \mathrm{~b}$ & $5.13 \mathrm{c}$ & $0.00 \mathrm{e}$ \\
Fantom & $9.77 \mathrm{~b}$ & $8.73 \mathrm{ab}$ & $8.60 \mathrm{a}$ & $5.63 \mathrm{~b}$ & $2.30 \mathrm{~d}$ & $0.00 \mathrm{e}$ \\
Sayar-314 & $9.73 \mathrm{~b}$ & $8.60 \mathrm{bc}$ & $8.70 \mathrm{a}$ & $5.37 \mathrm{a}$ & $5.00 \mathrm{c}$ & $0.00 \mathrm{e}$ \\
Erşan-92 & $10.37 \mathrm{a}$ & $9.40 \mathrm{a}$ & $7.33 \mathrm{bc}$ & $5.30 \mathrm{~b}$ & $5.00 \mathrm{c}$ & $3.53 \mathrm{~b}$ \\
\hline Ort. (Mean) & 9.52 & 8.49 & 7.06 & 5.62 & 4.90 & 1.99 \\
\hline LSD(0.05) & 0.520 & 0.707 & 0.927 & 0.589 & 0.271 & 0.451 \\
\hline
\end{tabular}

*: Aynı harf grubu içerisinde yer alan konular arasında (dikey) istatistiki olarak önemli düzeyde (0.05) bir farklılık bulunamamıştır

*Means shown with the same column (vertical) are not significantly differently at $p=0.05$ probability level.

\section{Bitki boyunun boğum sayısına oranı}

Çizelge 5'den, ekimden 46 gün sonra ölçülen bitki boyu/boğum sayısı değerinin 1.73 ile $2.46 \mathrm{~cm}$ arasında olduğu; 52 . günde 2.61 ile $2.82 \mathrm{~cm}$ arasında, 59. günde 2.46 ile $3.60 \mathrm{~cm}$ arasında; 66 . günde 2.96 ile $3.88 \mathrm{~cm}$
arasında; 73. günde 3.17 ile $4.19 \mathrm{~cm}$
arasında; 81. günde 3.15 ile $4.16 \mathrm{~cm}$
arasında; 88. günde 3.27 ile $4.15 \mathrm{~cm}$
arasında; 95. günde 3.28 ile $4.11 \mathrm{~cm}$
arasında; 103. günde 3.27 ile $4.09 \mathrm{~cm}$
arasında 110. günde 3.19 ile $4.10 \mathrm{~cm}$ 
arasında; 117. günde 3.25 ile $4.07 \mathrm{~cm}$ arasında 124. günde 3.24 ile $4.09 \mathrm{~cm}$ arasında; 132. günde 3.16 ile $4.04 \mathrm{~cm}$ arasında ve 138. günde ise 3.14 ile $4.03 \mathrm{~cm}$ arasında değiştiği izlenebilmektedir. Aynı çizelgeden, Carmen çeşidi hariç diğer çeşitlerde bitki boyu/boğum oranının ekimden 73 gün sonra azaldığı, 117. günden sonra bitkilerin gelişimini yavaşlattığı görülebilmektedir. Birim alanda istenen düzeyde verim alınabilmesi için bitki gelişiminin belirli bir dengede olması istenir. İhtiyaç duyulan miktardan fazla azot kullanımı ve fazla sulama bitkilerin vejetatif olarak gelişimine neden olmakta ve bitki başına çiçek sayısı ve buna bağlı olarak koza sayısı azalabilmektedir. Bitkiler belirli bir süre vejetatif olarak geliştikten sonra generatif devrede çiçek ve koza oluşumu ile birlikte besin elementleri koza oluşumunda harcanmaktadır. Bu yüzden bitkiler büyümelerini generatif olarak sürdürmektedirler (Kerby ve ark., 1993). Çizelge 5'den, orta erkenci Sayar-314 ve Erşan-92 çeşitlerinde bitki büyüme oranının daha yüksek çıktığı, bu durumun çeşitlerin uzun boylu olmasından kaynaklandığı düşünülmektedir.

Haftalık ölçümlerde çeşitler arasında farklılıklar olduğu görülmektedir. Bu durum, çeşitlerin farklı olgunlaşma gruplarına (BA119, DPL 388, Fantom çeşitleri erkenci, ST453, SG-125, DPL-5111, Sayar-314 ve Erşan-92 orta erkenci ve Carmen ve GW Teks geççi) ait olmasından kaynaklanmaktadır. İncelenen çeşitlerin büyüme düzenlerinde genel olarak bir denge olduğu görülmektedir. Özellikle tam taraklanma ve çiçeklenme döneminde, boy/boğum sayısı oranları büyüme kontrolünde kullanılmalıdır. Bu amaçla, pamuk çeşitleri üretime alınmadan önce boy/boğum sayısı oranlarının belirlenmesi en uygun verim için önemlidir (Silvertooth ve Norton, 1999).

\section{Son 5 Boğum uzunluğu $(\mathrm{cm})$}

Çizelge 6'dan, ekimden 46 gün sonra yapılan en son 5 boğum uzunluğunun 4.67 $\mathrm{cm}$ ile $6.27 \mathrm{~cm}$ arasında olduğu; 52. günde $4.27 \mathrm{~cm}$ ile $5.50 \mathrm{~cm}$ arasında, 59. günde 4.90 $\mathrm{cm}$ ile $7.47 \mathrm{~cm}$ arasında; 66. günde $5.13 \mathrm{~cm}$ ile $7.40 \mathrm{~cm}$ arasında; 73 günde $4.17 \mathrm{~cm}$ ile $4.70 \mathrm{~cm}$ arasında; 81 . günde $4.13 \mathrm{~cm}$ ile 4.37 $\mathrm{cm}$ arasında; 88 . günde $3.47 \mathrm{~cm}$ ile $4.03 \mathrm{~cm}$ arasında; 95 . günde $3.30 \mathrm{~cm}$ ile 3.90 arasında; 103. günde $3.20 \mathrm{~cm}$ ile $3.67 \mathrm{~cm}$ arasında; 110. günde $3.20 \mathrm{~cm}$ ile $3.50 \mathrm{~cm}$ arasında; 117. günde $3.10 \mathrm{~cm}$ ile $3.30 \mathrm{~cm}$ arasında; 124. günde $3.10 \mathrm{~cm}$ ile $3.27 \mathrm{~cm}$ arasında; 132. günde 3.17 ile $3.77 \mathrm{~cm}$ arasında ve 138. günde ise $3.13 \mathrm{~cm}$ ile 3.70 cm arasında değiştiği izlenebilmektedir. Bitki boyu gelişimi veya buna bağlı olarak boğumlar arası mesafenin uzunluğu bitkilerin genotipik farklılığın yanında, sıcaklık, nem, sulama ve fazla miktarda azot kullanımına bağlı olarak değişebilmektedir. Ayrıca, lokasyonlara göre değişen iklim koşulları da bitkilerin gelişimini ve buna bağlı olarak bitki boyunu etkileyebilmektedir (Çelik ve ark., 2009). Bulgularımız Özbek ve ark., (2005) bulgularından kısmen daha kısa olduğu, bu durumun ölçümde kullanılan yöntemin farklılığından kaynaklandığı düşünülmektedir. Aynı çizelgeden, Carmen çeşidi hariç diğer çeşitlerde en son 5 boğum uzunluğunun ekimden sonra 73. günden itibaren azaldığı, 117. günden sonra bitkilerin gelişimine tekrar başladığı görülebilmektedir. Bu durum, özellikle Ağustos ayının üçüncü haftasından itibaren sıcaklığın bitki gelişimi için normal koşullara dönmesinden kaynaklanmaktadır (Çopur ve Oğlakçı, 1997). Birim alanda istenen düzeyde verim alınabilmesi için bitki gelişiminin belirli bir 
dengede olması istenir. Bitkiler belirli bir süre vejetatif olarak geliştikten sonra generatif devrede çiçek ve koza oluşumu ile birlikte besin elementleri koza oluşumunda harcanmaktadır (Bölek ve ark., 2007). Çizelge 6'dan, orta erkenci Sayar-314 ve Erşan-92 çeşitlerinde en son 5 boğum uzunluğunun daha yüksek çıktığı, bu durum çeşitlerin uzun boylu olmasından kaynaklanabilmektedir. Haftalık ölçümlerde en son 5 boğum uzunluğu yönünden çeşitler arasında farklılıklar olduğu görülmektedir. En yüksek en son 5 boğum uzunluğunun ekimden 60-65 gün sonra oluştuğu Çizelge 6 'dan izlenebilmektedir. Bu süre özellikle bitkilerin çiçeklenme dönemine rastlamaktadır. Çiçeklenme döneminde bitkilerde yoğun bir şekilde karbonhidrat kullanıldığından besin ve su stresinden olumsuz yönde etkilenebilmektedir. Besin ve su stresi yanında, çeşitlerin farklı olgunlaşma gruplarına (BA-119, DPL 388, Fantom çeşitleri erkenci, ST-453, SG-125, DPL-5111, Sayar-314 ve Erşan-92 orta erkenci ve Carmen ve GW Teks geççi) ait olması da farklı son 5 boğum uzunluğu gruplarının oluşumuna neden olabilmektedir. Ayrıca, incelenen çeşitlerin en son 5 boğum uzunluğu değeri yönünden BÇÜBS ve boy/boğum oranı ile benzerlikler gösterdiği görülmektedir. Özellikle tam taraklanma ve çiçeklenme döneminde en son 5 boğum uzunluğu değerleri büyüme kontrolünde kullanılabilir. Bu amaçla, pamuk çeşitleri üretime alınmadan önce farklı azot ve sulama seviyelerine göre en son 5 boğum uzunluklarının belirlenmesi yararlı olacaktır. 
Çizelge 5. 2006 ve 2007 yıllarında, farklı pamuk çeşitlerinde ve farklı günlerde elde edilen ortalama bitki boyunun boğum sayısına oranı ile LSD testine göre oluşan gruplar

Table 5. Means of number of height to node number ratio according to some cultivars and LSD testing groups in years to 2006 and 2007

\begin{tabular}{|c|c|c|c|c|c|c|c|c|c|c|c|c|c|c|}
\hline \multirow[b]{2}{*}{$\begin{array}{l}\text { Çeşitler } \\
\text { Varieties }\end{array}$} & \multicolumn{14}{|c|}{ Ekimden sonraki gunler (Days of after sowing) (2006 yill year) } \\
\hline & $\begin{array}{c}46 \\
(21.06) \\
\end{array}$ & $\begin{array}{c}52 \\
(27.06) \\
\end{array}$ & $\begin{array}{c}59 \\
(04.07) \\
\end{array}$ & $\begin{array}{c}66 \\
(11.07)\end{array}$ & $\begin{array}{c}73 \\
(18.07) \\
\end{array}$ & $\begin{array}{c}81 \\
(26.07) \\
\end{array}$ & $\begin{array}{c}88 \\
(02.08) \\
\end{array}$ & $\begin{array}{c}95 \\
(09.08) \\
\end{array}$ & $\begin{array}{c}103 \\
(17.08)\end{array}$ & $\begin{array}{c}110 \\
(24.08) \\
\end{array}$ & $\begin{array}{c}117 \\
(31.08)\end{array}$ & $\begin{array}{c}124 \\
(06.09)\end{array}$ & $\begin{array}{c}132 \\
(14.09)\end{array}$ & $\begin{array}{c}138 \\
(20.09)\end{array}$ \\
\hline STV-453 & $1.98 \mathrm{~cd}^{*}$ & $2.45 \mathrm{ef}$ & $2.84 \mathrm{de}$ & $3.18 \mathrm{e}$ & $3.23 \mathrm{f}$ & $3.23 \mathrm{e}$ & $3.20 \mathrm{~g}$ & $3.19 \mathrm{~g}$ & 3.181 & $3.19 \mathrm{~g}$ & $3.13 \mathrm{f}$ & $3.13 \mathrm{e}$ & $3.12 \mathrm{~d}$ & $3.09 \mathrm{~g}$ \\
\hline SG-125 & $2.05 \mathrm{bcd}$ & 2.32 def & $2.87 \mathrm{de}$ & $3.33 \mathrm{~d}$ & $3.58 \mathrm{~cd}$ & $3.49 \mathrm{c}$ & $3.46 \mathrm{~cd}$ & $3.45 \mathrm{~d}$ & $3.43 \mathrm{e}$ & $3.41 \mathrm{~cd}$ & $3.40 \mathrm{c}$ & $3.37 \mathrm{c}$ & $3.32 \mathrm{c}$ & $3.32 \mathrm{~cd}$ \\
\hline BA-119 & $2.13 \mathrm{bc}$ & $2.39 \mathrm{de}$ & $2.91 \mathrm{~cd}$ & $3.39 \mathrm{c}$ & $3.51 \mathrm{~d}$ & $3.44 \mathrm{~d}$ & $3.35 \mathrm{e}$ & $3.34 \mathrm{e}$ & $3.33 \mathrm{f}$ & $3.33 \mathrm{e}$ & $3.28 \mathrm{de}$ & $3.29 \mathrm{~d}$ & $3.29 \mathrm{c}$ & $3.28 \mathrm{de}$ \\
\hline Carmen & $1.73 \mathrm{e}$ & $2.16 \mathrm{f}$ & $2.46 \mathrm{~g}$ & $2.96 \mathrm{f}$ & $3.17 \mathrm{f}$ & $3.15 \mathrm{f}$ & $3.27 \mathrm{f}$ & $3.28 \mathrm{f}$ & $3.28 \mathrm{~h}$ & $3.27 \mathrm{f}$ & $3.27 \mathrm{de}$ & $3.28 \mathrm{~d}$ & $3.28 \mathrm{c}$ & $3.25 \mathrm{e}$ \\
\hline DPL-388 & $1.91 \mathrm{~d}$ & $2.29 \mathrm{def}$ & $2.76 \mathrm{f}$ & $3.18 \mathrm{e}$ & $3.35 \mathrm{e}$ & $3.26 \mathrm{e}$ & 3.30 ef & 3.29 ef & $3.27 \mathrm{~h}$ & $3.26 \mathrm{f}$ & $3.25 \mathrm{e}$ & $3.24 \mathrm{~d}$ & $3.16 \mathrm{~d}$ & $3.14 \mathrm{f}$ \\
\hline DPL-4111 & $2.17 \mathrm{~b}$ & $2.47 \mathrm{~cd}$ & $2.97 \mathrm{c}$ & $3.36 \mathrm{~cd}$ & $3.61 \mathrm{c}$ & $3.49 \mathrm{~cd}$ & $3.42 \mathrm{~d}$ & $3.41 \mathrm{~d}$ & $3.39 \mathrm{f}$ & $3.36 \mathrm{de}$ & $3.34 \mathrm{~cd}$ & $3.34 \mathrm{c}$ & $3.31 \mathrm{c}$ & $3.31 \mathrm{~cd}$ \\
\hline GW Teks & $2.05 \mathrm{bcd}$ & $2.60 \mathrm{bc}$ & 2.83 ef & $3.33 d$ & $3.55 \mathrm{~cd}$ & $3.48 \mathrm{~cd}$ & $3.51 \mathrm{c}$ & $3.51 \mathrm{c}$ & $3.49 \mathrm{~d}$ & $3.45 c$ & $3.41 \mathrm{c}$ & $3.38 \mathrm{c}$ & $3.32 \mathrm{c}$ & $3.34 \mathrm{c}$ \\
\hline Fantom & $2.18 \mathrm{~b}$ & $2.64 a b c$ & $2.99 \mathrm{c}$ & $3.51 \mathrm{~b}$ & $3.70 \mathrm{~b}$ & $3.67 \mathrm{~b}$ & $3.61 \mathrm{~b}$ & $2.61 \mathrm{~d}$ & $3.61 \mathrm{c}$ & $3.59 \mathrm{~b}$ & $3.56 \mathrm{~b}$ & $3.59 \mathrm{~b}$ & $3.57 \mathrm{~b}$ & $3.55 \mathrm{~b}$ \\
\hline Sayar-314 & $2.46 \mathrm{a}$ & $2.82 \mathrm{a}$ & $3.51 b$ & $3.86 \mathrm{a}$ & $4.18 \mathrm{a}$ & $4.16 \mathrm{a}$ & $4.15 \mathrm{a}$ & $4.11 \mathrm{a}$ & $4.08 \mathrm{~b}$ & $4.08 \mathrm{a}$ & $4.07 \mathrm{a}$ & $4.09 \mathrm{a}$ & $4.00 \mathrm{a}$ & $3.97 \mathrm{a}$ \\
\hline Erşan-92 & $2.40 \mathrm{a}$ & $2.75 \mathrm{ab}$ & $3.60 \mathrm{a}$ & $3.88 \mathrm{a}$ & $4.19 \mathrm{a}$ & $4.12 \mathrm{a}$ & $4.12 \mathrm{a}$ & $4.11 a$ & $4.09 \mathrm{a}$ & $4.10 \mathrm{a}$ & $4.07 \mathrm{a}$ & $4.07 \mathrm{a}$ & $4.04 \mathrm{a}$ & $4.03 \mathrm{a}$ \\
\hline Ort. (Mean) & 2.11 & 2.47 & 2.97 & 3.40 & 3.61 & 3.55 & 3.54 & 3.53 & 3.52 & 3.51 & 3.48 & 3.48 & 3.44 & 3.43 \\
\hline \multirow[t]{2}{*}{$\operatorname{LSD}(0.05)$} & 0.172 & 0.188 & 0.077 & 0.054 & 0.077 & 0.054 & 0.054 & 0.054 & 0.005 & 0.054 & 0.077 & 0.054 & 0.054 & 0.054 \\
\hline & \multicolumn{14}{|c|}{ Ekimden sonraki günler (Days of after the sowing) (2007 yılı year) } \\
\hline $\begin{array}{l}\text { Çeşitler } \\
\text { Varieties }\end{array}$ & $\begin{array}{c}46 \\
(21.06)\end{array}$ & $\begin{array}{c}52 \\
(27.06)\end{array}$ & $\begin{array}{c}59 \\
(04.07)\end{array}$ & $\begin{array}{c}66 \\
(11.07)\end{array}$ & $\begin{array}{c}73 \\
(18.07)\end{array}$ & $\begin{array}{c}81 \\
(26.07)\end{array}$ & $\begin{array}{c}88 \\
(02.08)\end{array}$ & $\begin{array}{c}95 \\
(09.08)\end{array}$ & $\begin{array}{c}103 \\
(17.08)\end{array}$ & $\begin{array}{c}110 \\
(24.08)\end{array}$ & $\begin{array}{c}117 \\
(31.08)\end{array}$ & $\begin{array}{c}124 \\
(06.09)\end{array}$ & $\begin{array}{c}132 \\
(14.09)\end{array}$ & $\begin{array}{c}138 \\
(20.09)\end{array}$ \\
\hline STV-453 & $2.10 \mathrm{e}^{*}$ & $2.20 \mathrm{e}$ & $2.60 \mathrm{f}$ & 3.40 ef & $3.40 \mathrm{~b}$ & $3.27 \mathrm{e}$ & $3.37 \mathrm{~b}$ & $3.20 \mathrm{c}$ & $3.47 \mathrm{~b}$ & $3.47 \mathrm{de}$ & $3.27 \mathrm{~d}$ & $3.20 \mathrm{de}$ & $3.10 \mathrm{e}$ & $3.03 \mathrm{~cd}$ \\
\hline SG-125 & $2.30 \mathrm{~d}$ & $2.77 \mathrm{bc}$ & 2.87 def & 3.53 cdef & $3.77 \mathrm{~b}$ & $3.73 b$ & $3.67 \mathrm{~b}$ & $3.60 \mathrm{~b}$ & $3.43 b$ & $4.03 \mathrm{bc}$ & $3.67 \mathrm{bc}$ & 3.53 bcde & $3.40 \mathrm{c}$ & $3.30 \mathrm{~b}$ \\
\hline BA-119 & $2.30 \mathrm{~d}$ & $2.83 \mathrm{~b}$ & $3.10 \mathrm{~cd}$ & $3.80 \mathrm{bc}$ & $3.77 \mathrm{~b}$ & $3.67 \mathrm{bc}$ & $3.60 \mathrm{~b}$ & $3.43 b c$ & $3.53 \mathrm{~b}$ & $3.80 \mathrm{~cd}$ & $3.53 \mathrm{~cd}$ & $3.57 \mathrm{bcd}$ & $3.47 \mathrm{c}$ & $3.27 \mathrm{bc}$ \\
\hline Carmen & $1.90 \mathrm{f}$ & $2.43 d$ & 2.80 ef & $3.37 \mathrm{f}$ & $3.63 \mathrm{~b}$ & $3.40 \mathrm{de}$ & $3.33 \mathrm{~b}$ & $3.23 \mathrm{c}$ & $3.23 \mathrm{~b}$ & $3.50 \mathrm{de}$ & $3.47 \mathrm{~cd}$ & 3.40 cde & $3.23 \mathrm{de}$ & $3.13 \mathrm{bcd}$ \\
\hline DPL-388 & $2.43 \mathrm{~cd}$ & $2.70 \mathrm{c}$ & $3.03 \mathrm{de}$ & $3.47 \mathrm{def}$ & $3.43 \mathrm{~b}$ & $3.33 \mathrm{e}$ & $3.30 \mathrm{~b}$ & $3.23 \mathrm{c}$ & $3.30 \mathrm{~b}$ & $3.43 \mathrm{e}$ & $3.43 \mathrm{~cd}$ & $3.17 \mathrm{e}$ & $3.13 \mathrm{e}$ & $2.90 \mathrm{~d}$ \\
\hline DPL-4111 & $2.63 \mathrm{~b}$ & $2.83 \mathrm{~b}$ & $3.07 \mathrm{de}$ & $3.50 \mathrm{cdef}$ & $3.57 b$ & 3.43 cde & $3.40 \mathrm{~b}$ & $3.37 \mathrm{bc}$ & $3.27 \mathrm{~b}$ & 3.53 de & $3.40 \mathrm{~cd}$ & 3.27 cde & $3.17 \mathrm{e}$ & $3.10 \mathrm{bcd}$ \\
\hline GW Teks & $2.53 \mathrm{bc}$ & $2.70 \mathrm{c}$ & $3.03 \mathrm{de}$ & $3.73 \mathrm{~cd}$ & $3.77 \mathrm{~b}$ & 3.67 bc & $3.50 \mathrm{~b}$ & $3.60 \mathrm{~b}$ & $3.40 \mathrm{~b}$ & 3.70 cde & $3.47 \mathrm{~cd}$ & $3.63 \mathrm{bc}$ & $3.37 \mathrm{~cd}$ & $3.27 \mathrm{bc}$ \\
\hline Fantom & $2.63 \mathrm{~b}$ & $2.80 \mathrm{bc}$ & $3.37 \mathrm{bc}$ & 3.70 cde & $3.77 \mathrm{~b}$ & $3.63 \mathrm{bcd}$ & $3.57 \mathrm{~b}$ & $3.53 \mathrm{~b}$ & $3.50 \mathrm{~b}$ & $3.60 \mathrm{de}$ & $3.70 \mathrm{bc}$ & $3.83 \mathrm{ab}$ & $3.67 \mathrm{~b}$ & $3.63 \mathrm{a}$ \\
\hline Sayar-314 & $2.93 \mathrm{a}$ & $3.23 \mathrm{a}$ & $3.73 \mathrm{a}$ & $4.13 \mathrm{a}$ & $4.20 \mathrm{a}$ & $4.20 \mathrm{a}$ & $4.47 \mathrm{a}$ & $4.23 \mathrm{a}$ & $4.07 \mathrm{a}$ & $4.43 a$ & $4.10 \mathrm{a}$ & $4.13 a$ & $3.97 \mathrm{a}$ & $3.83 \mathrm{a}$ \\
\hline Erşan-92 & $2.83 \mathrm{a}$ & $3.17 \mathrm{a}$ & $3.60 a b$ & $4.10 \mathrm{ab}$ & $4.17 \mathrm{a}$ & $4.10 \mathrm{a}$ & $4.43 \mathrm{a}$ & $4.17 \mathrm{a}$ & $4.00 \mathrm{a}$ & $4.33 \mathrm{ab}$ & $3.90 \mathrm{ab}$ & $4.07 \mathrm{a}$ & $3.97 \mathrm{a}$ & 3.87 \\
\hline Ort. (Mean) & 2.46 & 2.77 & 3.12 & 3.67 & 3.75 & 3.64 & 3.66 & 3.56 & 3.52 & 3.78 & 3.59 & 3.58 & 3.45 & 3.33 \\
\hline LSD(0.05) & 0.172 & 0.133 & 0.277 & 0.302 & 0.372 & 0.249 & 0.497 & 0.287 & 0.330 & 0.339 & 0.343 & 0.368 & 0.163 & 0.254 \\
\hline
\end{tabular}

*: Aynı harf grubu içerisinde yer alan konular arasında (dikey) istatistiki olarak önemli düzeyde (0.05) bir farkıııık bulunamamıștır

*Means shown with the same column (vertical) are not significantly differently at $p=0.05$ probability level. 
Çizelge 6. 2006 ve 2007 yıllarında, farklı pamuk çeşitlerinde ve farklı günlerde elde edilen ortalama en son 5 boğum uzunluğu değerleri ile LSD testine göre oluşan gruplar

Table 6. Means of height of last 5 node according to some cultivars and LSD testing groups in years to 2006 and 2007

\begin{tabular}{|c|c|c|c|c|c|c|c|c|c|c|c|c|c|c|}
\hline \multirow{2}{*}{$\begin{array}{l}\text { Çeşitler } \\
\text { Varieties }\end{array}$} & \multicolumn{14}{|c|}{ Ekimden sonraki günler (Days of after the sowing) (2007 (yılı/year) } \\
\hline & $\begin{array}{c}46 \\
(21.06)\end{array}$ & $\begin{array}{c}52 \\
(27.06)\end{array}$ & $\begin{array}{c}59 \\
(04.07)\end{array}$ & $\begin{array}{c}66 \\
(11.07)\end{array}$ & $\begin{array}{c}73 \\
(18.07)\end{array}$ & $\begin{array}{c}81 \\
(26.07)\end{array}$ & $\begin{array}{c}88 \\
(02.08) \\
\end{array}$ & $\begin{array}{c}95 \\
(09.08)\end{array}$ & $\begin{array}{c}103 \\
(17.08)\end{array}$ & $\begin{array}{c}110 \\
(24.08)\end{array}$ & $\begin{array}{c}117 \\
(31.08)\end{array}$ & $\begin{array}{c}124 \\
(06.09)\end{array}$ & $\begin{array}{c}132 \\
(14.09)\end{array}$ & $\begin{array}{c}138 \\
(20.09)\end{array}$ \\
\hline STV-453 & $5.10 \mathrm{bc}^{*}$ & $4.90 \mathrm{de}$ & $6.87 \mathrm{bc}$ & $5.77 \mathrm{de}$ & $4.43 a b c$ & $4.37 \mathrm{a}$ & $3.87 \mathrm{abc}$ & $3.77 \mathrm{ab}$ & $3.50 \mathrm{~b}$ & $3.47 \mathrm{ab}$ & $3.20 \mathrm{abc}$ & $3.13 \mathrm{bc}$ & $3.23 \mathrm{~cd}$ & $3.17 \mathrm{c}$ \\
\hline SG-125 & $5.13 \mathrm{bc}$ & $5.50 \mathrm{a}$ & $6.63 \mathrm{~cd}$ & $6.30 \mathrm{c}$ & $4.67 \mathrm{a}$ & $4.27 \mathrm{a}-\mathrm{d}$ & $3.77 \mathrm{bc}$ & $3.57 \mathrm{bc}$ & $3.47 \mathrm{~b}$ & $3.37 \mathrm{~b}$ & $3.10 \mathrm{c}$ & $3.10 \mathrm{~cd}$ & $3.43 \mathrm{~b}$ & $3.50 \mathrm{ab}$ \\
\hline BA-119 & $5.40 \mathrm{bc}$ & $5.47 \mathrm{ab}$ & $6.77 \mathrm{c}$ & $7.00 \mathrm{ab}$ & $4.17 \mathrm{c}$ & $4.23 \mathrm{~b}-\mathrm{e}$ & $3.90 \mathrm{abc}$ & $3.73 \mathrm{ab}$ & $3.50 \mathrm{~b}$ & $3.47 \mathrm{ab}$ & $3.20 \mathrm{abc}$ & $3.20 \mathrm{ab}$ & $3.37 \mathrm{bc}$ & $3.37 b c$ \\
\hline Carmen & $4.67 \mathrm{c}$ & $4.27 f$ & $4.90 \mathrm{f}$ & $5.13 \mathrm{f}$ & $4.27 \mathrm{bc}$ & $4.30 \mathrm{abc}$ & $3.47 \mathrm{~d}$ & $3.30 \mathrm{c}$ & $3.20 \mathrm{c}$ & $3.20 \mathrm{c}$ & $3.10 \mathrm{c}$ & $3.10 \mathrm{~cd}$ & $3.17 \mathrm{~d}$ & $3.13 c$ \\
\hline DPL-388 & $5.10 \mathrm{bc}$ & $4.70 \mathrm{e}$ & $5.87 \mathrm{e}$ & $6.17 \mathrm{~cd}$ & $4.57 \mathrm{a}$ & $4.33 \mathrm{ab}$ & $4.03 \mathrm{a}$ & $3.87 \mathrm{a}$ & $3.50 \mathrm{~b}$ & $3.37 \mathrm{~b}$ & $3.30 \mathrm{a}$ & $3.27 a$ & $3.40 \mathrm{~b}$ & $3.47 \mathrm{ab}$ \\
\hline DPL-5111 & $5.37 \mathrm{bc}$ & $5.10 \mathrm{bcd}$ & $7.50 \mathrm{a}$ & $6.17 \mathrm{~cd}$ & $4.63 \mathrm{a}$ & $4.37 \mathrm{a}$ & $3.90 \mathrm{abc}$ & $3.83 a b$ & $3.67 \mathrm{a}$ & $3.50 \mathrm{a}$ & $3.17 \mathrm{bc}$ & $3.10 \mathrm{~cd}$ & $3.23 \mathrm{~cd}$ & $3.37 \mathrm{bc}$ \\
\hline GW Teks & $5.23 \mathrm{bc}$ & $5.30 \mathrm{abc}$ & $6.43 \mathrm{~d}$ & $5.50 \mathrm{ef}$ & $4.53 \mathrm{ab}$ & $4.20 \mathrm{cde}$ & $3.83 a b c$ & $3.83 \mathrm{ab}$ & $3.60 a b$ & $3.50 \mathrm{a}$ & $3.10 \mathrm{c}$ & $3.03 \mathrm{~d}$ & $3.23 \mathrm{~cd}$ & $3.50 \mathrm{ab}$ \\
\hline Fantom & $4.77 \mathrm{bc}$ & $4.97 \mathrm{cde}$ & $6.63 \mathrm{~cd}$ & $5.27 f$ & $4.23 \mathrm{c}$ & $4.23 \mathrm{~b}-\mathrm{e}$ & $3.70 \mathrm{~cd}$ & $3.77 \mathrm{ab}$ & $3.60 a b$ & $3.40 a b$ & $3.13 \mathrm{bc}$ & $3.10 \mathrm{~cd}$ & $3.77 \mathrm{a}$ & $3.70 \mathrm{a}$ \\
\hline Sayar-314 & $5.53 \mathrm{ab}$ & 5.13abcd & $7.13 b$ & $7.40 \mathrm{a}$ & $4.57 \mathrm{a}$ & $4.17 \mathrm{de}$ & $3.83 a b c$ & $3.90 \mathrm{a}$ & $3.57 a b$ & $3.50 \mathrm{a}$ & $3.23 \mathrm{ab}$ & $3.20 \mathrm{ab}$ & $3.33 \mathrm{bc}$ & $3.50 \mathrm{ab}$ \\
\hline Erşan-92 & $6.27 \mathrm{a}$ & $4.80 \mathrm{de}$ & $7.47 \mathrm{a}$ & $6.63 \mathrm{bc}$ & $4.70 \mathrm{a}$ & $4.13 \mathrm{e}$ & $3.97 a b$ & $3.87 \mathrm{a}$ & $3.67 \mathrm{a}$ & $3.50 \mathrm{a}$ & $3.17 \mathrm{bc}$ & $3.17 \mathrm{bc}$ & $3.23 \mathrm{~cd}$ & $3.47 \mathrm{ab}$ \\
\hline Ort. (Mean) & 5.26 & 5.01 & 6.62 & 6.13 & 4.48 & 4.26 & 3.83 & 3.74 & 3.53 & 3.43 & 3.17 & 3.14 & 3.34 & 3.42 \\
\hline LSD (0.05) & 0.833 & 0.384 & 0.277 & 0.470 & 0.297 & 0.121 & 0.249 & 0.277 & 0.153 & 0.109 & 0.109 & 0.077 & 0.153 & 0.277 \\
\hline \multirow{2}{*}{$\begin{array}{l}\text { Çeşitler } \\
\text { Varieties }\end{array}$} & \multicolumn{14}{|c|}{ Ekimden sonraki günler (Days of after the sowing) (2007 yılı/year) } \\
\hline & $\begin{array}{c}46 \\
(21.06)\end{array}$ & $\begin{array}{c}52 \\
(27.06)\end{array}$ & $\begin{array}{c}59 \\
(04.07)\end{array}$ & $\begin{array}{c}66 \\
(11.07)\end{array}$ & $\begin{array}{c}73 \\
(18.07)\end{array}$ & $\begin{array}{c}81 \\
(26.07)\end{array}$ & $\begin{array}{c}88 \\
(02.08)\end{array}$ & $\begin{array}{c}95 \\
(09.08)\end{array}$ & $\begin{array}{c}103 \\
(17.08)\end{array}$ & $\begin{array}{c}110 \\
(24.08)\end{array}$ & $\begin{array}{c}117 \\
(31.08)\end{array}$ & $\begin{array}{c}124 \\
(06.09)\end{array}$ & $\begin{array}{c}132 \\
(14.09)\end{array}$ & $\begin{array}{c}138 \\
(20.09)\end{array}$ \\
\hline STV-453 & $4.37 \mathrm{~cd}^{*}$ & $6.73 \mathrm{f}$ & $8.80 \mathrm{~b}$ & $8.80 \mathrm{~d}$ & $10.07 \mathrm{ab}$ & $7.67 \mathrm{e}$ & $6.33 \mathrm{~cd}$ & $4.53 \mathrm{~d}$ & $4.40 \mathrm{de}$ & $4.93 \mathrm{~d}$ & $4.93 \mathrm{bc}$ & $4.53 \mathrm{e}$ & $5.53 \mathrm{~d}$ & $5.40 \mathrm{c}$ \\
\hline SG-125 & $4.43 \mathrm{~cd}$ & 7.33 ef & 10.07 a & $10.07 \mathrm{c}$ & $10.00 \mathrm{ab}$ & $9.27 \mathrm{c}$ & $7.00 \mathrm{bcd}$ & $6.40 \mathrm{bc}$ & $5.40 \mathrm{bc}$ & $5.73 \mathrm{bcd}$ & $4.67 \mathrm{c}$ & $5.67 \mathrm{~cd}$ & $5.47 \mathrm{~d}$ & $5.73 \mathrm{c}$ \\
\hline BA-119 & $4.63 \mathrm{bcd}$ & $8.13 \mathrm{~cd}$ & $9.50 a b$ & $10.53 \mathrm{c}$ & $11.07 \mathrm{a}$ & $9.20 \mathrm{~cd}$ & $7.80 \mathrm{~b}$ & $5.33 \mathrm{~cd}$ & $4.93 \mathrm{cde}$ & $5.40 \mathrm{~cd}$ & $4.67 \mathrm{c}$ & $5.33 \mathrm{de}$ & $6.07 \mathrm{~cd}$ & $5.87 \mathrm{c}$ \\
\hline Carmen & $3.63 \mathrm{~d}$ & $6.73 \mathrm{f}$ & $8.33 \mathrm{~b}$ & $9.00 \mathrm{~d}$ & $9.80 \mathrm{ab}$ & $9.13 \mathrm{~cd}$ & $7.40 \mathrm{bc}$ & $5.07 \mathrm{~cd}$ & $5.53 \mathrm{bc}$ & $6.00 \mathrm{abc}$ & $4.73 \mathrm{c}$ & $5.73 \mathrm{~cd}$ & $5.73 \mathrm{~d}$ & $5.87 \mathrm{c}$ \\
\hline DPL-388 & $4.77 \mathrm{bcd}$ & 6.80 ef & $8.73 \mathrm{~b}$ & $10.00 \mathrm{c}$ & $8.40 c$ & $8.00 \mathrm{de}$ & $6.27 \mathrm{~cd}$ & $6.47 \mathrm{bc}$ & $5.53 \mathrm{bc}$ & $5.93 \mathrm{abc}$ & $5.13 \mathrm{bc}$ & $5.73 \mathrm{~cd}$ & $6.00 \mathrm{~cd}$ & $5.67 \mathrm{c}$ \\
\hline DPL-5111 & $5.80 \mathrm{ab}$ & $7.53 \mathrm{de}$ & $8.47 \mathrm{~b}$ & $10.13 \mathrm{c}$ & $10.00 a b$ & $8.93 \mathrm{~cd}$ & $7.53 \mathrm{~b}$ & $7.47 a b$ & $5.33 \mathrm{bcd}$ & $5.60 \mathrm{~cd}$ & $4.67 \mathrm{c}$ & $5.73 \mathrm{~cd}$ & $5.87 \mathrm{~cd}$ & $6.07 c$ \\
\hline GW Teks & $5.67 \mathrm{abc}$ & $9.07 \mathrm{ab}$ & $9.40 a b$ & $10.67 \mathrm{bc}$ & $10.47 \mathrm{a}$ & $9.53 b c$ & $7.20 \mathrm{bcd}$ & $6.40 \mathrm{bc}$ & $4.87 \mathrm{cde}$ & $6.13 \mathrm{abc}$ & $5.33 \mathrm{bc}$ & $6.47 b c$ & $6.87 c$ & $6.93 \mathrm{~b}$ \\
\hline Fantom & $5.97 \mathrm{ab}$ & $8.23 \mathrm{~cd}$ & $8.47 \mathrm{~b}$ & $8.73 \mathrm{~d}$ & $9.07 \mathrm{bc}$ & $7.40 \mathrm{e}$ & $6.07 \mathrm{~d}$ & $5.20 \mathrm{~cd}$ & $4.13 \mathrm{e}$ & $6.60 \mathrm{a}$ & $6.47 a$ & $9.13 \mathrm{a}$ & $9.93 \mathrm{a}$ & $7.93 \mathrm{a}$ \\
\hline Sayar-314 & $6.40 \mathrm{a}$ & $8.70 \mathrm{bc}$ & $10.20 \mathrm{a}$ & $12.07 \mathrm{a}$ & $10.33 \mathrm{ab}$ & $11.07 \mathrm{a}$ & $9.40 \mathrm{a}$ & $8.00 \mathrm{a}$ & $7.67 \mathrm{a}$ & $6.53 \mathrm{ab}$ & $5.73 \mathrm{ab}$ & $7.27 \mathrm{~b}$ & $8.13 \mathrm{~b}$ & $8.13 \mathrm{a}$ \\
\hline Erşan-92 & $5.47 \mathrm{abc}$ & $9.47 a$ & $10.47 \mathrm{a}$ & $11.47 \mathrm{ab}$ & $10.60 \mathrm{a}$ & $10.60 \mathrm{ab}$ & $8.07 \mathrm{~b}$ & $7.13 \mathrm{ab}$ & $5.93 \mathrm{~b}$ & $6.13 \mathrm{abc}$ & $5.73 \mathrm{ab}$ & $8.93 \mathrm{a}$ & $9.33 \mathrm{a}$ & $8.67 \mathrm{a}$ \\
\hline Ort. (Mean) & 5.11 & 7.87 & 9.24 & 10.15 & 9.98 & 9.08 & 7.31 & 6.20 & 5.37 & 5.90 & 5.21 & 6.45 & 6.89 & 6.63 \\
\hline LSD (0.05) & 1.362 & 0.746 & 1.185 & 0.870 & 1.270 & 1.265 & 1.196 & 1.444 & 0.990 & 0.844 & 0.936 & 0.943 & 1.077 & 0.839 \\
\hline
\end{tabular}

*: Aynı harf grubu içerisinde yer alan konular arasında (dikey) istatistiki olarak önemli düzeyde $(0.05)$ bir farklıık bulunamamıştır

*Means shown with the same column (vertical) are not significantly differently at $p=0.05$ probability level. 
Kütlü pamuk verim, birinci el kütlü oranı ve beyaz çiçek üstü boğum sayı sının 5'e ulaşma gün sayısı

2006 ve 2007 yıllarında pamuk çeşitlerine göre elde edilen kütlü pamuk verimi $\left(\mathrm{kg} \mathrm{da}{ }^{1}\right)$, birinci el kütlü pamuk verimi (\%) ve beyaz çiçek üstü boğum sayısının 5'e ulaşma gün sayısı (gün/çeşit) değerleri Çizelge 7'de verilmiştir.

Çizelge 7. 2006 ve 2007 yıllarında, farklı pamuk çeşitlerinden elde edilen ortalama kütlü pamuk verimi, birinci el kütlü pamuk oranı ve beyaz çiçek üstü boğum sayısı (BÇÜBS)'nın 5'e ulaşma gün sayısı ile LSD testine göre oluşan gruplar

Table 7. Means of seed cotton yields, first picking ratio and the number of days required for the number of nodes above white flower to reach 5 according to some cultivars and LSD testing groups in years to 2006 and 2007

\begin{tabular}{|c|c|c|c|c|c|c|}
\hline \multirow[t]{2}{*}{$\begin{array}{l}\text { Çeşitler } \\
\text { Varieties }\end{array}$} & \multicolumn{2}{|c|}{$\begin{array}{l}\text { Kütlü pamuk verimi } \\
\qquad\left(\mathrm{kg} \mathrm{da}^{-1}\right) \\
\text { Seed cotton yield }\end{array}$} & \multicolumn{2}{|c|}{$\begin{array}{l}\text { Erkencilik oranı } \\
\text { (\%) } \\
\text { Easliness ratio }\end{array}$} & \multicolumn{2}{|c|}{$\begin{array}{c}\text { (BÇÜBS)'nın 5'e } \\
\text { ulaşma gün sayısı (gün çeşit }{ }^{-1} \text { ) } \\
\text { Days of reach to NAWF-5 }\end{array}$} \\
\hline & 2006 & 2007 & 2006 & 2007 & 2006 & 2007 \\
\hline STV-453 & $487.41 a^{*}$ & $454.12 \mathrm{a}$ & $96.00 \mathrm{bcd}$ & $95.30 \mathrm{ab}$ & $94.0 b^{*}$ & $96.0 \mathrm{~b}$ \\
\hline SG-125 & $328.19 \mathrm{f}$ & $318.31 \mathrm{e}$ & $96.76 \mathrm{abc}$ & $92.87 \mathrm{~b}$ & $87.0 \mathrm{c}$ & $89.0 \mathrm{c}$ \\
\hline BA-119 & $455.33 \mathrm{ab}$ & $432.14 a b$ & $97.73 \mathrm{ab}$ & $95.57 \mathrm{ab}$ & $87.0 \mathrm{c}$ & $89.0 \mathrm{c}$ \\
\hline Carmen & 386.22 de & 391.73 c & $87.31 \mathrm{f}$ & $81.35 \mathrm{c}$ & $101.0 \mathrm{a}$ & $103.0 \mathrm{a}$ \\
\hline DPL-388 & 394.16 cde & $386.74 \mathrm{c}$ & $98.01 \mathrm{a}$ & $98.72 a b$ & $87.0 \mathrm{c}$ & $89.0 \mathrm{c}$ \\
\hline DPL-5111 & 359.97 e & $345.14 \mathrm{~d}$ & $97.58 \mathrm{abc}$ & $96.28 \mathrm{ab}$ & $87.0 \mathrm{c}$ & $89.0 \mathrm{c}$ \\
\hline GW Teks & $338.54 \mathrm{f}$ & 323.15 de & $94.39 \mathrm{de}$ & $94.20 \mathrm{ab}$ & $94.0 \mathrm{~b}$ & $89.0 \mathrm{c}$ \\
\hline Fantom & $408.98 \mathrm{bcd}$ & 387.62 c & $98.33 \mathrm{a}$ & 98.97 a & $80.0 \mathrm{~d}$ & $82.0 \mathrm{~d}$ \\
\hline Sayar-314 & $423.32 \mathrm{bcd}$ & $420.91 b$ & $93.81 \mathrm{e}$ & $92.95 \mathrm{~b}$ & $94.0 \mathrm{~b}$ & $89.0 \mathrm{c}$ \\
\hline Erşan-92 & $439.69 \mathrm{bc}$ & $423.53 \mathrm{~b}$ & $95.96 \mathrm{~cd}$ & $94.84 \mathrm{ab}$ & $94.0 \mathrm{~b}$ & $89.0 \mathrm{c}$ \\
\hline $\begin{array}{l}\text { Ortalama } \\
\text { Mean }\end{array}$ & 402.18 & 388.34 & 95.59 & 94.11 & 90.50 & 90.40 \\
\hline LSD (0.05) & 46.72 & 24.03 & 1.75 & 5.94 & 2.49 & 1.80 \\
\hline
\end{tabular}

*: Aynı harf grubu içerisinde yer alan konular arasında (dikey) istatistiki olarak önemli düzeyde (0.05) bir farklılık bulunamamıştır

*Means shown with the same column (vertical) are not significantly differently at $p=0.05$ probability level

Çizelge 7'den kütlü pamuk veriminin 2006 yilında $328.19 \mathrm{~kg} \mathrm{da}^{-1}$ ile $487.41 \mathrm{~kg} \mathrm{da}^{-1}$ arasında değiştiği ve ortalamanın $402.18 \mathrm{~kg}$ $\mathrm{da}^{-1}$ olduğu, 2007 yılında ise $318.31 \mathrm{~kg} \mathrm{da}^{-1}$ ile $454.12 \mathrm{~kg} \mathrm{da}^{-1}$ arasında değiştiği ve ortalamanın $388.34 \mathrm{~kg} \quad \mathrm{da}^{-1}$ olduğu izlenebilmektedir. Kütlü pamuk verimi genotipik bir özellik olup, çeşitlerin çevre ile olan uyumu sonucu oluşmaktadır. Orta erkenci STV-453 çeşidinin diğer orta erkenci, erkenci (Fantom) ve geç̧̧i (Carmen) çeşitlerine göre daha yüksek verim oluşturduğu aynı çizelgeden izlenebilmektedir. Güneydoğu Anadolu Bölgesinde özellikle Harran Ovasında Sıcaklık
43-44 ${ }^{\circ} C^{\prime}$ ye kadar çıkmaktadır. Saptanan verim değerleri aynı zamanda çeşitlerin sıcaklık stresine olan tolerans durumlarını da göstermektedir. Nitekim Demirel ve ark. (2016) tarafından yapılan sıcaklığa toleranslık çalışmasında, Stoneville 453 ve BA-119 çeşitlerinin tarla koşullarına paralel olarak sıcaklığa toleranslı olduğu, bu nedenle anılan çeşitlerin verim durumları yanında sıcaklığa toleranslı çeşit ıslahında ebeveyn olarak seçilmesi gerektiği bildirilmiştir.

Çizelge 7'den, 2006 yılında, beyaz çiçek üstü boğum sayısının (BÇÜBS=5'e ulaşma gün sayılarının 80 ile 101 gün arasında değiştiği, ortalama 90.50 gün olduğu, 2007 yılında ise 
82 ile 103 gün arasında değiştiği ve ortalamanın 90.40 gün olduğu izlenebilmektedir. Aynı çizelgeden, en yüksek $B C ̧ U ̈ B S=5$ 'e ulaşma gün sayısı değerinin Carmen, en düşük $B C ̧ U ̈ B S=5$ 'e ulaşma gün sayısının ise Fantom ve DPL-388 ve DPL5111 çeşitlerinden elde edildiği görülebilmektedir. Bu durum, Fantom, DPL388 ve DPL-5111 çeşitlerinin diğer çeşitlere göre daha erken olgunlaşmaya başladığını göstermektedir. Pamukta fizyolojik olarak erkenci çeşitler erken çiçek oluşturmakta ve belli bir süreden sonra çiçeklenme kesilmekte ve kozalar olgunlaşarak açmaktadır. Dolayısıyla erken olgunlaşan bitkiler erken koza açabilmektedir. Erkenciliği belirleyen diğer bir unsur ekim tarihinden birinci pozisyonda en üst beyaz çiçek üstü boğum sayısının 5'e düştüğü gün sayısıdır. Aynı tarihte bazı çeşitler çiçek oluştururken bazıları taraklanma döneminde olabilmektedir. (Bölek, (2007), Khan, (2003) ve Soomro ve ark., (2005)'in değişik pamuk çeşitleri ile yaptıkları çalışmada; erken dönemde olgunlaşan çeşitlerin $B C ̧ U ̈ B S=5^{\prime} \mathrm{e}$ ulaşma gün sayılarının diğer çeşitlere göre daha erken oluştuğunu ve $B C ̧ U ̈ B S=5$ 'e ulaşma gün sayısının erkencilik kriteri olarak kullanılabileceğini bildirmektedir. Aynı çizelgeden birinci el kütlü pamuk oranı yönünden en yüksek değerin Fantom, DPL388 ve DPL-5111 çeşidinde ve en düşük değerin ise Carmen çeşidinde oluştuğu görülmektedir. Dolayısıyla birinci el kütlü pamuk oranı ile $B C ̧ U ̈ B S=5$ 'e ulaşma gün sayısı değerleri birbirlerini doğrulamaktadır. Bu durum, DPL-388, DPL-5111 ve Fantom çeşitlerinin erkenci olduğu ve erkencilik ıslahı çalışmalarında ebeveyn olarak kullanılabileceği gibi BÇÜBS'nın 5'e ulaşma gün sayısının da erkencilik kriteri olarak kullanılabileceğini göstermektedir.

\section{Sonuçlar}

Pamukta optimum verim için vejetatif ve generatif gelişim dönemlerinin belirli bir denge içerisinde olması gerekmektedir. $\mathrm{Bu}$ dengeyi, çeşit seçimi, sulama, gübreleme, zirai mücadele ve bitki büyüme düzenleyicilerinin kullanımı etkileyebilmektedir. Pamuk çeşitlerinden en yüksek verimi almak için bitki gelişiminin iyi bilinmesi gerekir. Taraklanma başlangııından maksimum çiçeklenme ve bundan 20-25 gün sonrasına kadar geçen süre verimi etkileyen önemli bir dönemdir. Bu dönemde bitkilerin su, besin ve bitki zararlıları gibi etmenlerin stresine maruz kalmamaları gerekmektedir. Yetiştirme sezonu boyunca bitkilerin strese maruz kalıp kalmadıkları; bitki boyu, bitki boy boğum oranı, beyaz çiçek üstü boğum sayısı ve son beş boğum uzunluğu gibi özellikler bu amaçla kullanılmaktadır. Çalışma sonucunda, özellikle beyaz çiçek üstü boğum sayısının çiçeklenme ve meyvelenme döneminde bitki yönetiminde aktif olarak kullanılabileceği sonucuna varılmıştır. Ayrıca, yaygın bir şekilde erkencilik kriteri olarak kullanılan birinci el kütlü pamuk oranının yanında, beyaz çiçek üstü boğum sayısının 5'e düşme gün sayısı özelliği de güvenli bir şekilde kullanılabilir.

\section{Kaynaklar}

Anonymous, 1989. User's Guide to MSTATC, An Analysis of Agronomic Research Experiments. Michigan State University, USA.

Anonim, 2006. GAP Toprak ve Su Kaynakları Araştırma Enstitüsü Müdürlüğü, Şanlıurfa.

Anonim, 2009. Şanlıurfa Meteoroloji Bölge Müdürlüğü İklim Veri Değerleri, Şanlıurfa.

Bourland F.M., Oosterhius, D.M., Tugwell, N.P., Cochran, MJ., 1992. Reading the Plant for Efficient Management. In: Proc. Beltwide Cotton Conferences. (Ed. D.J. Herber and D.A. Richter) pp. 146-148. 
Bölek Y., Oğlakçı, M,, Bardak, A., 2005. Pamuk tarımında kullanılan bitki izleme teknikleri. Akdeniz Üniversitesi Ziraat Fakültesi Tarla Bitkileri Bölümü, Türkiye VI. Tarla Bitkileri Kongresi Bildirileri, 5-9 Eylül, Antalya, Cilt I, s. 335-338.

Bölek, Y., 2007. Phenological Characteristics of Eight Cotton Genotypes under Irrigated and Non-Irrigated Conditions. KSU Journal of Science and Engineering, 10(2): 111117.

Bölek, Y., Oğlakçı, M., Kıllı, F., 2007. Pamukta (Gossypium spp.) Erkenciliği Belirleyen Faktörler ve Üretim Planlaması. KSÜ Fen ve Mühendislik Dergisi, 10 (1): 116-125.

Çelik, İ., Önal, İ., Çetinkaya, M., 2009. Antalya Koşullarında Çukurova-1518 Pamuk Çeşidinin Bitki İzleme Yöntemleri ìle Bitki Gelişiminin Değerlendirilmesi. Batı Akdeniz Tarımsal Araştırma Enstitüsü, Derim Dergisi 26 (2): 42-56.

Çopur, O., Oğlakçı, M., 1997. Harran Ovası Koşullarında Bazı Pamuk Çeşitlerinde Çiçeklenme ve Meyvelenme Düzeninin Saptanması. Harran Üniversitesi Ziraat Fakültesi Dergisi, 1 (2): 19-28.

Çopur, O., 2016. Lif Bitkileri (Çağrılı Bildiri). 20232071 Vizyonuyla TOÇ BIR-SEN Tarım Kongresi. 8-10 Nisan 2016, Kızılcahamam, Ankara (Basımda).

Demirel, U., Çopur, O., Gür, A., 2016. Screening of Cotton (Gossypium hirsutum L.) for Heat Tolerance Using Multi-trait Approach under Controlled Environment Conditions. Plant Breeding, 135 (1): 80-89.

Gençer, O., Yelin, D., 1983. Pamuk Bitkisinde (Gossypium hirsutum L.) Erkencilik Kriterlerinin Kalıtımı ve Verimle İlişkileri Üzerinde Bir Araştırma. Tarım ve Orman Bakanlığı Bölge Pamuk Araştırma Enstitüsü Yayınları, Yayın No: 40, Adana.

Iqbal, M., Chang, M.A., Mahmud, A., Iqbal, M.Z., Hassan, M., Islam, N.U., 2003. Maturity of Cotton Cultivars in Multan as Determined by Node above White Flower. Asian Journal of Plant Science, 2 (3): 325-330.

Khan, U.Q., 2003. Monitoring the growth and development of cotton plant using main stem node counts. Asian Journal of Plant Sciences, 2(8): 593-596

Landivar, J.A., Benedict, J.H., 1996. Monitoring system for the management of cotton growth and fruiting. Texas A\&M University, Texas Agricultural Experiment Station Bulletin B-2, USA.
Kerby, T.A., Horrocks, R.D., Plant, R.E, 1993. Plant Monitoring to Quantity Vegetative Vigor. Cotton Physiology Conferences. Proceedings Beltwide Cotton Conference. National Cotton Council. Memphis. pp. 1177-1180.

McPherson, G.R., Whimore, R., Gwyn, J., Vasek, J., Greenly, B. 1995. Use of Plant Mapping to Measure Maturity of Cotton Cultivars. In: Proc. Beltwide Cotton Conferences. (Ed. D.J. Herber and D.A. Richter) pp. 552556.

Oosterhius, D.M., Bourland, F.M., Tugwell, N.P., 1993. Basis for the Nodes-Above White Flower Cotton Monitoring System. Cotton Physiology Conferences.. Proceedings Beltwide Cotton Conference, pp. 11811183, NCC, Memphis, USA.

Oosterhuis, D.M., Robertson, W.C., 2000. The Use Plant Growth Regulators and Other Additives in Cotton Production. Proceedings of the 2000 Cotton Research Meeting. AAES Special Report 198, Arkansas, USA.

Özbek, N., Bintaş, E., Yılmaz, E., Beşenk, Z.Y., 2005. Pamuk Bitkisinde Farklı Bitki İzleme Teknikleri Kullanılarak Bitki Gelişiminin İzlenmesi ille Su Yönetimi. Proje No: TAGEM/TA/03/02/02/005, Nazili/Aydın.

Silvertooth, J.C., Norton, E.R., 1999. Cotton Monitoring and Management System. College of Agricultural the University of Arizona, USA.

Soomro, A.R, Anjum, R., Umar, A., Chang, M.A., Soomoro, S.R, Soomro, N. 2005. Comparison of Earliness Through Nodes above White Flower (NAWF) in Upland Cotton. The Indus Cottons, 2(2): 50-54.

Yolcu, S., 2009. Pamukta (Gossypium hirsutum L.) Farklı Azot Doz ve Uygulama Zamanlarının Verim ve Verim Unsurları İle Bitki Büyüme ve Gelişmesini İzleme Parametrelerine Etkisi. KSU Fen Bilimleri Enstitüsü, Tarla Bitkileri ABD, Yayınlanmamış Doktora Tezi, 136 sayfa, Kahramanmaraş.

Teague, TG., Tugwell, N.P., Danforth, D.M., Oosterhuis, D.M., 2000. Cotman in Cotton Research. Proceedings of the 2000 Cotton Research Meeting, pp. 198-202, USA.

Worley, S.J.R., Harmon, H.R., Harrel, D.C., Culp, T.W., 1976. Ontogenetic Model of Cotton Yield. Crop Science, 16: 30-34. 